\title{
Wet Comminution in Stirred Media Mills ${ }^{\dagger}$
}

\author{
Arno Kwade and Jörg Schwedes \\ Kwade + Schwedes Zerkleinerungstechnik* \\ Institute of Mechanical Process Engineering \\ Technical University of Braunschweig, Germany**
}

\begin{abstract}
The importance of stirred media mills in various industries as well as in research is steadily increasing because the quality requirements of comminution products, e.g. the product fineness, rise continuously. This paper gives a survey of different mill designs and of the influence of various operating parameters on the specific energy consumption. The specific energy necessary for a certain product fineness depends above all on the stress intensity, which is among other things a function of the grinding media size and the circumferential stirrer speed. At similar stress intensities, the influence of the stirrer and grinding chamber geometry is small and scale-up using the specific energy is usually possible. Moreover residence time behaviour, wear of grinding media and autogenous comminution are discussed.
\end{abstract}

\section{Introduction}

Stirred media mills are increasingly used for the fine and ultrafine grinding of minerals, ceramic materials, paint pigments, chemical products, microorganisms and other materials. In these mills which are mainly operated wet, the product particles are reduced in size between loose grinding media usually made of glass, steel or ceramic materials. Due to a very high number of stress events per unit time and unit volume and due to an appropriate stress intensity in the production of very fine particles, the specific energy consumption of stirred media mills is less than that of tumbling ball mills. The importance of stirred media mills increases steadily because of an increasing demand for fine and very fine particles and because of the advantages of stirred media mills compared with other mills. Therefore, many developments regarding minimization of specific energy, separation of very small grinding media, production of narrow particle size distributions and wear protection have been made in the last few years. Besides this, stirred media mills are increasingly the subject of scientific study, so that recently many new results have been published. Above all this paper covers experimental results, whereas simulation results using the population balance model or other models are not discussed.

\footnotetext{
* Consultants, Rebenring 33, 38106 Braunschweig, Germany

${ }^{* *}$ Volkmaroder Str. 4/5, 38104 Braunschweig, Germany

+ Received August 1, 1997
}

\section{History of development and different mill designs}

Originally, tumbling ball mills were often used for wet fine and ultrafine grinding. But since the power consumption of tumbling ball mills is limited by the number of revolutions at which the grinding media are centrifugated at the chamber wall, the power density is relatively small. Thus, for the production of fine and ultrafine powders, very long comminution times are necessary. To improve the efficiency in fine grinding, in 1928 Szegvari (in [1]) proposed a mill with a vertical stationary grinding chamber in which spherical grinding media are moved by a slowly rotating agitator. An advanced design of this mill built in 1950 is shown in Figure 1. Such lowspeed stirred media mills, also called "Attritors", with circumferential speeds up to approximately 6 $\mathrm{m} / \mathrm{s}$ are still built and used, mainly for the fine grinding of minerals and ceramic materials. Parallel to the further development of this mill (e.g. increase in length/diameter ratio of the vertical chamber), high-speed stirred media mills were developed, which were operated with circumferential speeds of 8 to $20 \mathrm{~m} / \mathrm{s}$ and with smaller grinding media. The industrial breakthrough of high-speed stirred media mills occurred in 1948 with the introduction of DuPont's "sand mill", which has been primarily applied as a pigment grinder in the paint industry. The product suspension is pumped through the vertical grinding chamber of the "sand mill" from the bottom to the open top, where the grinding 


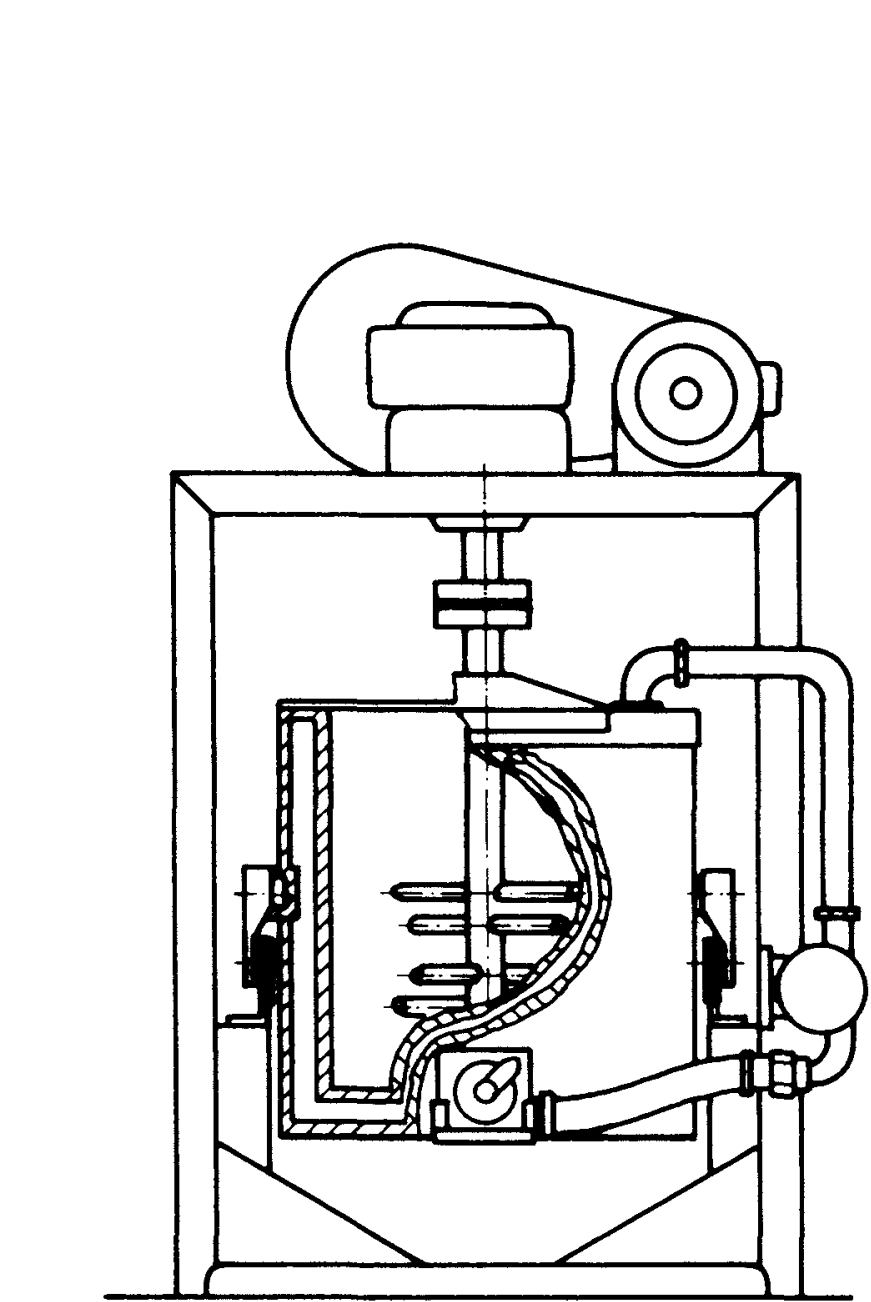

Fig. 1 Low-speed stirred media mill (Attritor) [1]

media are held back by a fixed sieve cage.

Since the power input and/or the volumetric power density of these open top mills are limited by the formation of spouts and other reasons (e.g. emission of solvents, inclusion of air, problems in processing highly viscous suspensions), these open top mills were largely replaced by closed-type mills. The grinding chamber of these closed stirred media mills can be arranged horizontally or vertically and is usually equipped with a water-jacket for cooling purposes. Usually 70 to $85 \%$ of the free grinding chamber volume is filled with a bulk of grinding media. Depending on the feed size and the feed material, different grinding media sizes (usually between $200 \mu \mathrm{m}$ and $4000 \mu \mathrm{m}$ ) and different grinding media materials (e.g. glass, steel and ceramic materials) are employed. The grinding media are moved by a stirrer with circumferential speeds of up to $20 \mathrm{~m} / \mathrm{s}$, so that centrifugal acceleration rates of more than fifty times the acceleration due to gravity can be achieved. As a typical example of a closed-type stirred media mill the design principle of a mill with a disc stirrer is shown in Figure 2 . The mill is equipped with a rotating gap for the separation of the grinding media. Today, closedtype stirred media mills are built with grinding chamber volumes of less than 1 litre (laboratory

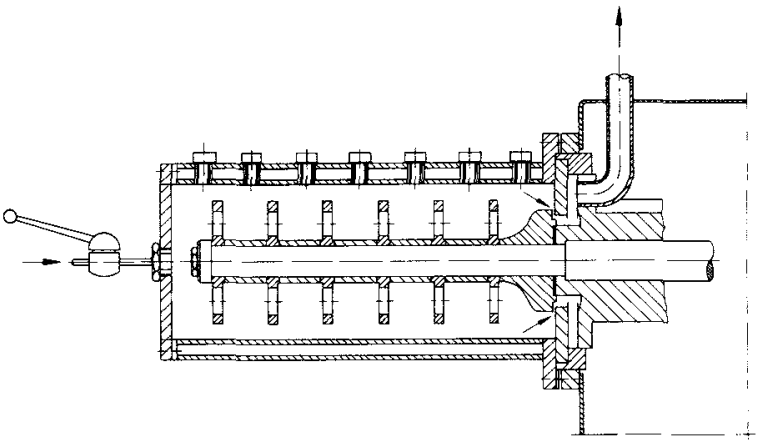

Fig. 2 Design principle of a closed-type stirred media mill with disc stirrer

scale) up to more than $1 \mathrm{~m}^{3}$ and with drive powers of more than $1 \mathrm{MW}$ [2].

A large number of different types of closed stirred media mills were developed by industry, especially in the last 10 years. The various mill designs differ above all in their chamber and stirrer geometry as well as in the separation device, which allows free discharge of the product but prevents the grinding media leaving the mill. Usually, the grinding media are held back in the grinding chamber by a screen (e.g. flat screens, screen cartridges [3], rotating or stationary cylindrical screens) or by a rotating gap (see Figure 2). In principle, the width of the rotating gap or the mesh width of the screen should be at least half the size of the grinding media. Usually, a rotating gap featuring self. cleaning properties is used for the processing of highly viscous suspensions. But rotating gaps are limited by the tolerance in the gap width and the relatively high pressure drop due to a very narrow gap width. Because grinding media with sizes of a few hundred microns are increasingly used, screens are being increasingly used instead of rotating gaps. They are usually designed and fixed such that they cause no dead zones in the grinding chamber, are exchangeable without having to empty the grinding chamber (screen cartridges), and/or that contact of the grinding media with the screen can be largely avoided by utilising the centrifugal force inside the mill or even by using a special kind of rejectorwheel classifier [2]. Due to specially designed grinding chamber geometries, the danger of accumulation and blocking of grinding media in front of the separation device can be significantly reduced.

Concerning the chamber and stirrer geometry, a distinction between three types of stirred media mills can be made :

- Stirred media mill with disc stirrer

- Stirred media mill with pin-counter-pin stirrer

- Annular gap geometry 
Figure 3 shows schematically the three different geometries. The simplest stirrer geometry is the disc stirrer. Here, the energy is transferred from the stirrer to the grinding media/product mixture mainly by adhesion. The discs can be provided with holes, slots, slits, etc. and/or are fixed eccentrically, so that as a result of displacement forces, additional energy can be transferred from the stirrer to the grinding media/product mixture. The pin-counterpin stirrer moves the grinding media/product mixture mainly by means of displacement forces. Especially if counter-pins (rotor/stator-system) are used, the power density is larger than that of a disc stirrer at an identical circumferential speed. The highest power density can be obtained in a grinding chamber of an annular gap mill. The width of the annular gap is usually small, i.e. approximately 5 to 20 times the grinding media diameter. Often, these mills consist of a smooth rotor and a smooth chamber wall, so that energy is transferred only by adhesion forces. In this case, the power density is very uniform and the residence time distribution is narrower than that of disc or pin-counter-pin stir-

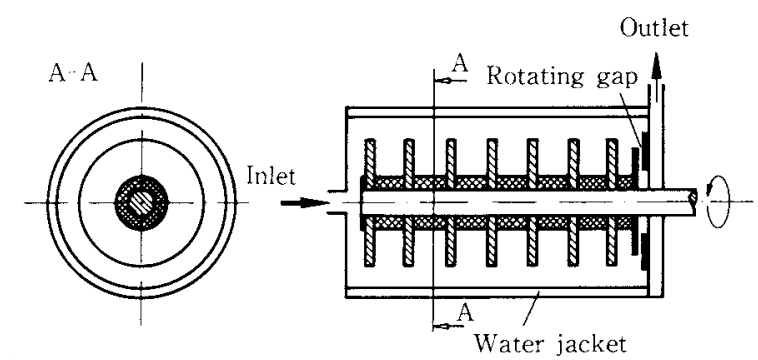

a) Disc stirrer

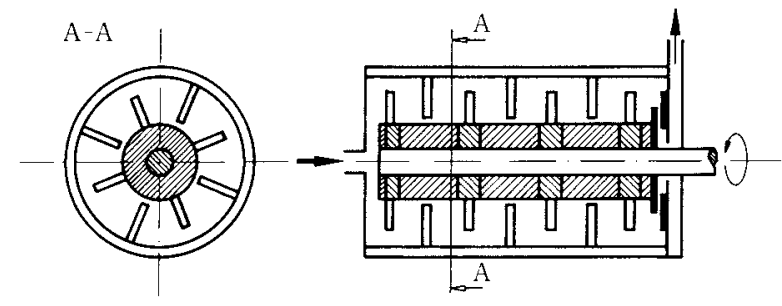

b) Pin-counter-pin stirrer

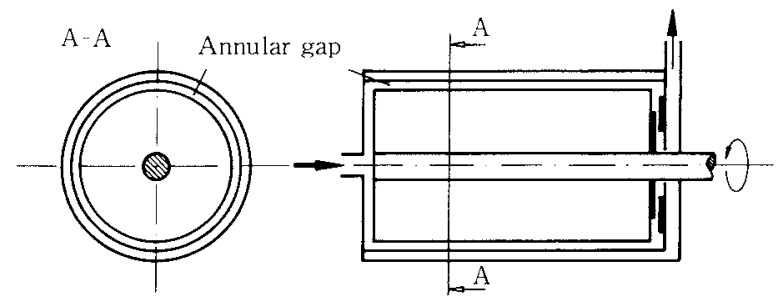

c) Annular gap mill

Fig. 3 Characteristic chamber and stirrer geometries rers. Some annular gap mills are also equipped with pins so that displacement forces act besides adhesion forces, permitting an even higher energy density to be obtained. Recently, annular gap mills have become very popular and most manufacturers of stirred media mills offer a specially designed annular gap mill. Annular gap mills are built with a single or double conical annular gap, with a single cylindrical or double cylindrical annular gap, or with a rotor shaped like a flat disc. Especially in some of the annular gap mills, the danger of accumulation and blocking of grinding media in front of the separation device is significantly reduced by means of an internal circulation of the grinding media.

\section{Motion of the grinding media}

Bosse [4] was the first to investigate the motion of grinding media in a stirred media mill. Based on his work, further experimental and theoretical investigations were published [5-7]. Recently, numerical calculations concerning the flow field, the distribution of the specific energy and the motion of single grinding beads in a grinding chamber with disc stirrer have been carried out by Blecher, Kwade and Schwedes [8,9]. Although the calculations are based on the steady-state laminar stirring of a Newtonian fluid without grinding media, in principle the results correspond to the published experimental investigations.

A result of this study is given in Figure 4, in which a section of the grinding chamber, i.e. the upper part of a disc with the volumes shown next to the disc, is shown. On the left side of the disc, profiles of the tangential fluid velocity are depicted for a Reynolds number of 2000 . On the right side, stationary trajectories of single beads in the radialaxial plane are presented. The profiles of the tangential fluid velocity, i.e. the velocity perpendicular to the plane of representation show that the tangential velocity is nearly constant except in the vicinity of the discs. Near the discs, high gradients of the tangential velocity and, therefore, zones of high power density exist in which the power density is higher than the mean power density. This zone is shown on the right side of the disc. Another zone of high power density is located at the grinding chamber wall. Although the volume of these zones is only about $10 \%$ of the net grinding chamber volume, at a Reynolds number of 2000 , approximately $90 \%$ of the power is consumed in the zones of high power 


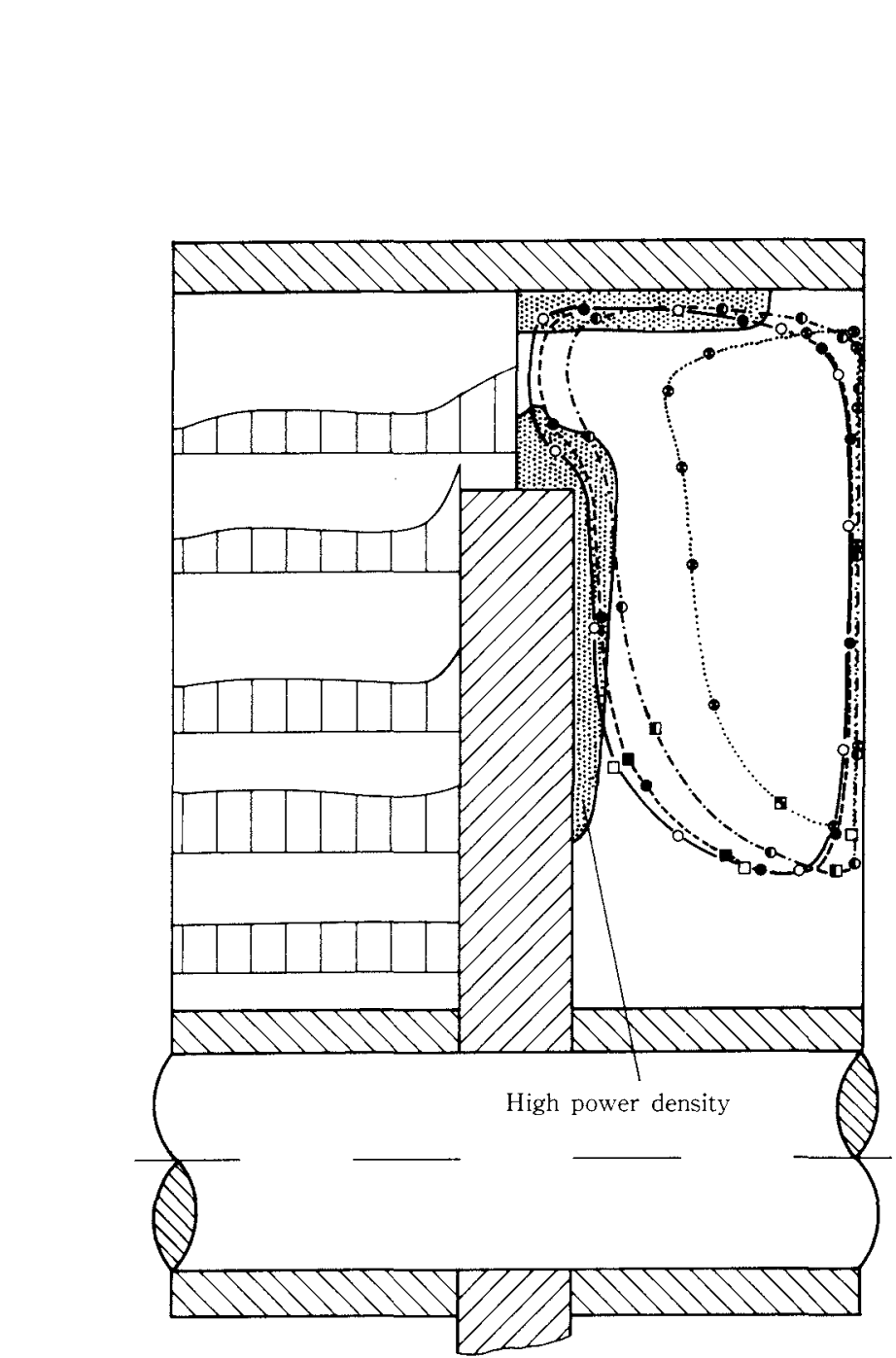

Fig. 4 Profiles of the tangential fluid velocity and stationary trajectories of single grinding beads in the axial-radial plane $[8,9]$

density.

Besides in tangential direction, the fluid and therefore the grinding beads also rotate in axial and radial direction. The beads move thereby through the zones of high energy density. In the zone around the stirrer discs, the grinding media are accelerated towards the grinding chamber wall. At the grinding chamber wall, the grinding media are turned round and move to the plane of symmetry between two discs. The grinding media move along the symmetry plane from the chamber wall back to the stirrer shaft because of the condition of continuity.

\section{Effect of geometry and operating parameters on the comminution result}

Several investigations concerning stirred media mills are occupied with the determination of the effect of various operating parameters on the relationship between product fineness and grinding time. But as the investigations show, the grinding time necessary for a certain product fineness cannot describe the influence of the several operating parameters on the comminution result. Therefore, this paper will focus on the relationship between the product fineness and the specific energy input (net energy input related to the product mass or net power input related to the product mass flow rate, respectively). The specific energy is well known to be an important influencing variable in most comminution processes. In the case of high-speed stirred media mills, Stehr, Weit and Schwedes [10-14] found on the basis of a large number of continuous grinding experiments with limestone as the grinding material that the specific energy input $E_{m}$ is the main influencing variable on the comminution result for a wide parameter range. As it can be seen in Figure 5, in a first approximation, the specific energy describes the influence of mill size, circum ferential speed of the stirrer, $v_{t}$, solids concentration of the suspension, $c_{V}$, density of the grinding media, $\rho_{\mathrm{GM}}$, and throughput, $\dot{\mathrm{V}}_{\mathrm{Susp}}$, on the product fineness (integral mean size $\bar{x}_{1,3}$ ). Therefore, control of the specific energy input is often sufficient to guarantee a certain product quality in grinding plants [15].

Further investigations published more recently (Stehr [16], Mankosa et al. [17], Stadler et al. [18], Bunge [19,20], Thiel [21,22], Kwade et al. [23,24], Joost [25]), show that besides the specific energy input, the size of the grinding beads greatly affects the comminution result. For example, the influence of the media size on the relationship between the specific energy and the product fineness (median size $\mathrm{x}_{50}$ ) is shown in Figure 6 for batch comminution of limestone using glass beads. It can be seen that the specific energy consumption can be decreased considerably by adapting the grinding media size to suit the comminution problem. Using glass beads of a size larger than or equal to $838 \mu \mathrm{m}$, smaller beads yield a finer product at fixed specific energy inputs. For smaller glass beads (399 $\mu \mathrm{m}-661$

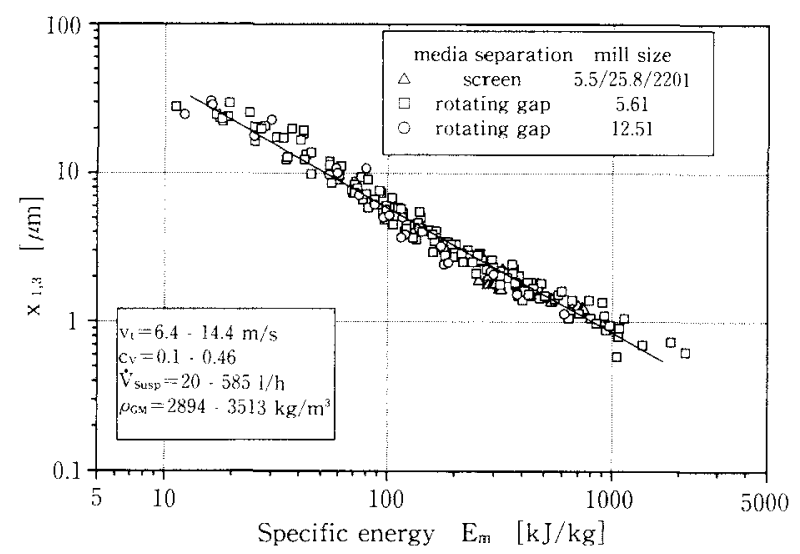

Fig. 5 Relationship between product fineness (integral mean size $\mathrm{x}_{1.3}$ ) and specific energy for the comminution of limestone 
P $\mu \mathrm{m}$ N the position of the curve depends on the spe cific energy input: for low specific energies, larger glass beads yield a finer product, whereas for high specific energies, smaller glass beads are advantageous. For very small beads (97 $\mu \mathrm{m}$ and $219 \mu \mathrm{m})$, no progress in the product fineness can be found.

Moreover, Kwade et al. [23,24] and Reinsch et al. [26] show that as well as by the media size, the relationship between the product fineness and the specific energy is affected by the circumferential speed of the discs and the grinding media density. This influence is shown in Figure 7 , in which the relationship between the median size obtained at a specific energy input of $1000 \mathrm{~kJ} / \mathrm{kg}$ and the diame ter of the grinding media is presented. The six curves plotted for different circumferential speeds of the discs and different densities of the grinding media have a characteristic shape. With increasing grinding media size, the median size of the product first declines down to a minimum. At this minimum, the corresponding grinding media size is most advantageous for a specific energy input of $1000 \mathrm{~kJ} /$

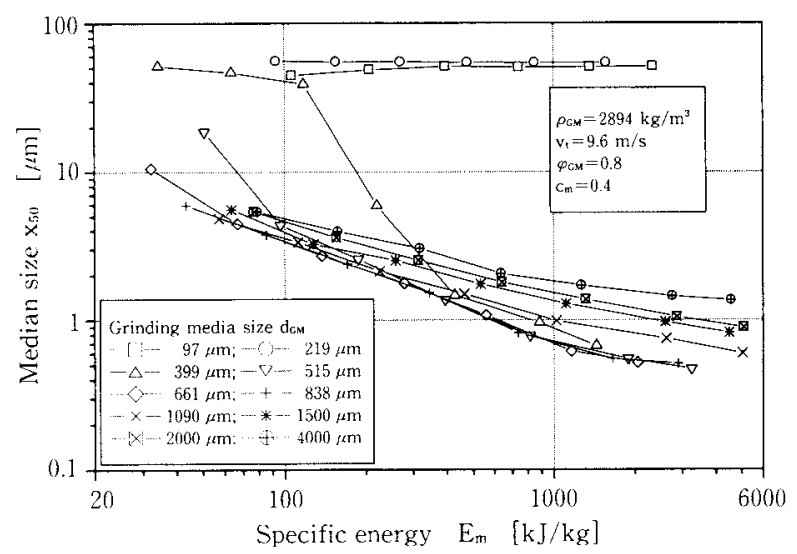

Fig. 6 Effect of grinding media size on the relationship between product fineness and specific energy

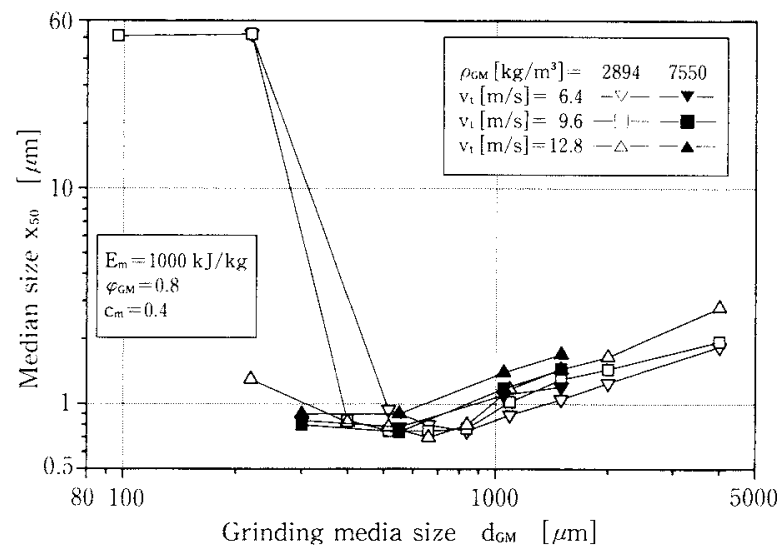

Fig. 7 Relationship between product fineness and media size for a constant specific energy input, but different circumferential speeds of the discs and different media densities kg. For grinding media sizes larger than the optimum size, the median size of the product increases with increasing grinding media diameter and, moreover, with increasing circumferential velocity of the discs as well as with increasing media density.

The following explanation can be given as a reason for the influence of the different operating parameters on the relationship between product fineness and specific energy [24]: The specific energy input can be considered as the product of the number of stress events and the specific energy consumed at a single stress event (i.e. the energy related to the product mass stressed between two grinding media). A measure for the number of stress events is the so-called stress number and a measure for the specific energy consumed at a single stress event is the stress intensity. The stress intensity in stirred media mills is determined above all by the kinetic energy of the grinding media. Therefore, the stress intensity is proportional to the mass of a grinding medium (bead) and to the square of the tangential velocity of the grinding media. Assuming that the tangential velocity of the grinding media is proportional to the circumferential speed of the discs, that the elasticity of the feed material is much less than that of the grinding media, and that only single particles are stressed intensively between the grinding media, the following expression can be taken as a measure of the stress intensity :

$$
\mathrm{SI}_{\mathrm{GM}}=\mathrm{d}_{\mathrm{GM}}^{3} \cdot \rho_{\mathrm{GM}} \cdot \mathrm{v}_{\mathrm{t}}{ }^{2}
$$

The parameter $\mathrm{SI}_{\mathrm{GM}}$, which is called stress intensity of the grinding media, is determined by the operating parameters (media size, $\mathrm{d}_{\mathrm{GM}}$, media density $\rho_{\mathrm{GM}}$, and circumferential speed of the discs, $\mathrm{v}_{\mathrm{t}}$ ) and is constant during a comminution process. If the elasticity of the feed material is about the same or higher than that of the grinding media material (e. g. in grinding of ceramic materials), Young's modulus of the feed, $\mathrm{Y}_{\mathrm{F}}$, and Young's modulus of the grinding media material, $\mathrm{Y}_{\mathrm{GM}}$, have to be taken into account. The larger the Young's modulus of the feed material is compared to that of the media material, the larger is the deformation of the grinding media at each stress event and the less energy is transfer red from the grinding media to the product particle. According to Becker and Schwedes [27], this influence can be described by the following definition of the stress intensity, which is a measure for the stress intensity acting on the feed or product particle : 


$$
\mathrm{SI}_{\mathrm{P}}=\mathrm{d}_{\mathrm{GM}}^{3} \cdot \rho_{\mathrm{GM}} \cdot \mathrm{V}_{\mathrm{t}}{ }^{2} \cdot\left(1+\frac{\mathrm{Y}_{\mathrm{F}}}{\mathrm{Y}_{\mathrm{GM}}}\right)^{-1}
$$

The influence of the stress intensity on the relationship between the product fineness and the specific energy is shown in the following by means of the comminution of limestone, where the elasticity of the feed material is much less than that of the grinding media material. In Figure 8 the median sizes, which are already shown in Figure 7 , are related to the stress intensity $\mathrm{SI}_{\mathrm{Gm}}$. It can be seen that for a constant specific energy input, the stress intensity determines the product fineness. The specific energy and the stress intensity are the two main influencing variables for the comminution of limestone in stirred media mills.

Almost no comminution progress is obtained at small stress intensities because the stress intensities are too low for breaking the feed particles. Therefore, multiple stressing and more energy are required. With increasing stress intensity, the product fineness increases until a minimum is reached. At this fineness, the stress intensity has an optimum value. If the stress intensity is further increased while the specific energy input is held constant, the product fineness decreases because the number of stress events, and above all, the energy utilization (newly created surface related to the energy input) of each stress event decrease. Because of the decrease in energy utilization, the decrease in product fineness due to the decrease in stress number is higher than the increase in product fineness due to the increase in stress intensity. For example, the new surface achieved by stressing a particle volume only once with a certain stress intensity is smaller than the new surface created by stressing this parti. cle volume twice with half stress intensity.

For different specific energy inputs, different relationships between the stress intensity $\mathrm{SI}_{\mathrm{GM}}$ and

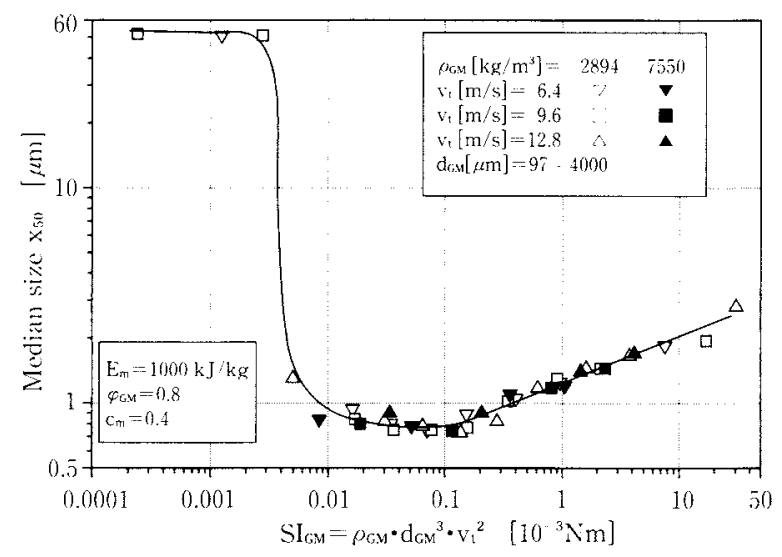

Fig. 8 Influence of stress intensity on median size for a specific energy input of $1000 \mathrm{~kJ} / \mathrm{kg}$ the product fineness and thus different optimum values of the stress intensity exist. With increasing specific energy and therefore increasing product fineness, the optimum stress intensity decreases because with decreasing particle size, lower energies and lower forces of pressure are necessary to break a product particle. Therefore, the optimum and most advantageous stress intensity always depends on the demanded product fineness.

Besides the specific energy and the stress intensity, the filling ratio of the grinding media (bulk volume of the grinding media related to the grinding chamber volume) also affects the comminution result : Thiel [21], Joost [25] and Kwade [23] have shown that at a constant specific energy input and at a constant stress intensity of the grinding media, the product fineness increases with increasing filling ratio of the grinding media. Depending on other operating parameters and on the chamber geometry, the optimum filling ratio is in the range of 0.75 to 0.85 . For filling ratios lower than the optimum value, Joost [25] and Kwade [23] found that the influence of the filling ratio on the comminution result can be described by the product of the specific energy and the filling ratio of the grinding media. This finding is shown in Figure 9 for the comminution of limestone and can be explained as follows: In stirred media mills, the energy is transferred from the stirrer to the grinding media and the suspension. The larger the amount of grinding media inside the grinding chamber and therefore the larger the filling ratio is, the larger is the part of the energy which is transferred to the grinding media and not to the suspension. Thus, the product of the filling ratio of grinding media and the specific energy is a measure for that portion of the specific energy which can be used for comminution.

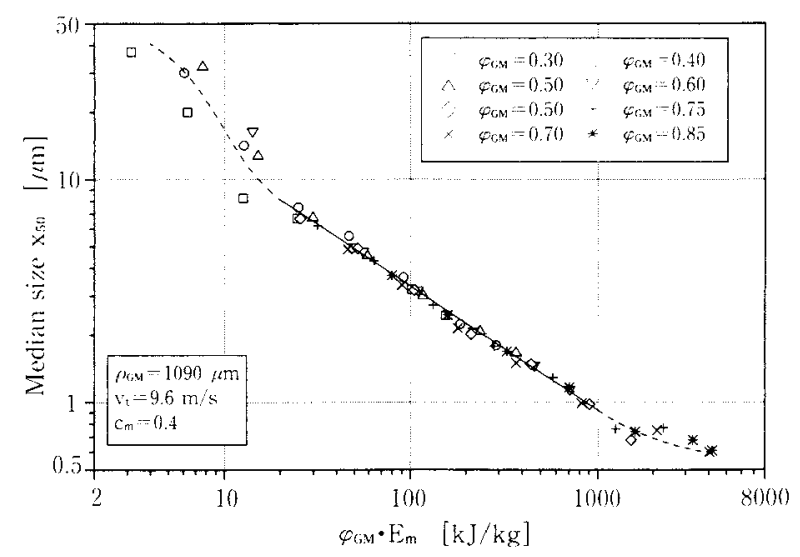

Fig. 9 Product fineness as a function of the product of the specific energy and the filling ratio of the grinding media 
The solids concentration of the suspension is another operating parameter which can be described in a first approximation by the specific energy. But at low solids concentrations, more specific energy is required to achieve the same product fineness [23]. A possible reason for this behaviour is that at low solids concentrations, it is not at every grinding media contact that a product particle is stressed between the grinding media. Besides low solids concentrations, also high solids concentrations can make larger specific energy consumptions necessary for producing a certain product fineness because of disadvantageous suspension viscosities $[21,25,28]$. To overcome this problem, grinding aids or dispersants can be used to reduce the suspension viscosity. But as experiments of Wang et al. [28] show, dispersants have to be used carefully because too large an amount of dispersants can lead to higher specific energy consumptions.

Instead of with the specific energy, the product fineness can be correlated with the so-called stress number (sometimes also called stress frequency). The stress number is a measure for the number of stress events in a mill and can describe the influence of the grinding time as well as the influence of several operating parameters on the product fineness. Various authors [18-21,23,24] show that by choosing an appropriate relation for the stress number or stress frequency, the effect of several operating parameters on the comminution result can be described. For the comminution of limestone, Kwade and Schwedes $[23,24]$ show that for a constant stress intensity, a certain relationship between the product fineness and the stress number exist. In contrast to these results, the effect of the stress intensity is different for the disintegration of microorganisms $[19,20]$ and for the desagglomeration of pigments [18]. For the case that the stress intensity is higher than the stress intensity necessary for the disintegration of a microorganism or for the desagglomeration of an agglomerate, only one relationship between the disintegration rate or the product fineness and the stress number exist. The reason is that if a microorganism is disintegrated or an agglomerate is broken, a higher stress intensity has no additional advantage.

\section{Effect of mill size and mill design on the com- minution result}

Weit and Schwedes [12,13] and recently Karbstein et al. [29] as well as Kwade [24] investigated the effect of the mill size on the specific energy necessary to obtain a certain product fineness. Weit used seven stirred media mills with disc stirrer and net volumina between 5.5 and 200 litres. Besides the mill size, he varied the circumferential speed of the discs, $v_{t}$, the volume flow rate, $\dot{V}_{\text {Susp }}$, and the solids concentration by volume, $c_{v}$. The comminution results shown in Figure $\mathbf{5}$ prove that the specific energy required for a certain product fineness is more or less independent of the mill size. The results published by Karbstein et al. confirm the results of Weit for grinding chamber net volumes down to approximately 1 1. But the comminution experiments of Karbstein et al. and Kwade also show that by using grinding chambers with net volumes less than 11 , the specific energy necessary for a certain product fineness increases. Among other things, the increase of the specific energy requirement using very small grinding chamber volumes can be attributed to a change in the stress intensity: At an unchanged circumferential stirrer speed, the centrifugal acceleration and thus the stress intensity of the grinding media increase with decreasing mill size. Therefore, as long as the stress intensity remains in the range of the optimum stress intensity, although the mill size has changed (see Figure 8), the effect of the mill size on the specific energy consumption is small. But if the stress intensity is much larger than the optimum stress intensity (for example, because of a relatively large grinding media size), the specific energy necessary for a certain product fineness increases with decreasing mill size.

Since the specific energy consumption is independent of the mill size for a wide range of mill sizes, the specific energy required for a certain product fineness can be determined by means of comminution experiments in a small mill. This specific energy has to be supplied to the large mill by choosing an appropriate flow rate and an appropriate circumferential stirrer speed. The required circum ferential stirrer speed can be determined by using the power characteristic diagram, which is well known in stirring processes and where the Newton number is plotted versus the Reynolds number [11-13].

Joost and Schwedes [25,30], Reinsch et al. [26] and Karbstein et al. [29,31] investigated whether chamber and stirrer geometry influence the relationship between the product fineness and the specific energy. Joost and Karbstein et al. used three different geometries according to the three different 
types shown in Figure 3, whereas Reinsch et al. investigated a mill with a disc stirrer and different types of annular gap mills. All investigations show that at a certain specific energy input and at a comparable stress intensity, similar median sizes of the product are obtained with the different mill designs. Differences were found in the widths of the particle size distributions. For example, Figure 10 shows particle size distributions obtained at four specific energy inputs using three different mill designs $[25,30]$. The particle size distributions prove that the narrowest particle size distribution can be achieved using the annular gap geometry because of a narrow residence time distribution and because of a relatively uniform power density or stress intensity, respectively. The widest particle size distributions were found for the pin-counter-pin stirrer because of intense radial mixing and axial remixing. The products achieved with the disc stirrer have particle size distributions which range between the others.

\section{Transport behaviour and residence time distri- bution}

As mentioned before, the width of the particle size distribution depends on the residence time distribution of the mill and thus on the axial flow through the grinding chamber. For the description of the axial transport of the product particles through the grinding chamber, two models can be used: Axial dispersion model $[11,24,32,33]$ and cell model with backmixing [24,33,34]. The axial dispersion model bases on the notion that a mixing motion superposes the convective axial transport over the entire length of the grinding chamber. On the other hand, in the cell model with backmixing, the grind-

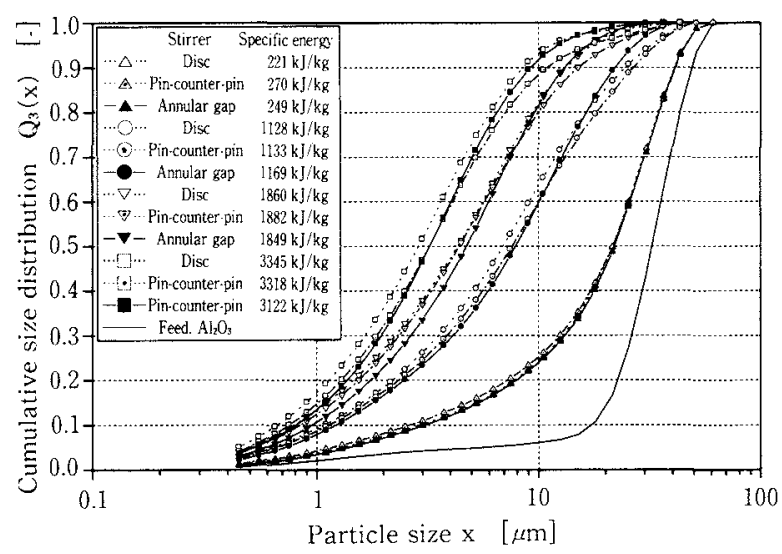

Fig. 10 Comparison of grinding results at the same specific energy input; three different grinding chamber geometries $[25,30]$ ing chamber is divided into several cells. In the case of a grinding chamber with a disc stirrer, the number of cells corresponds to the number of discs and the cells are bounded by the symmetry planes between two discs. The product suspension flows through all cells from the inlet to the outlet. Besides that, a so-called backmixing flow rate connects two adjacent cells in both directions because of the backmixing behaviour.

Up to now, the applicability of the two different transport models has only been proven for a mill with disc stirrer: Heitzmann [33], Berthiaux et al. [34] and Kwade [24] have shown that the residence time behaviour of a mill with disc stirrer can be described better by the cell model with backmixing than with the axial dispersion model. This is shown in Figure 11, in which a residence time distribution measured by Kwade is compared to the distributions calculated with the two models.

The residence time behaviour of the mill determines the residence time distribution of the product particles if the product flows only once through the grinding chamber. But often more than one pass is necessary to obtain the required product fineness. This can be done by using a cascade of mills or by pendulum operation. Besides the multi-pass mode, the circuit mode is very common, especially for the grinding of pigments where small batches are usual. Here, the suspension is pumped from a storage tank through the mill and then returned to the same tank $[18,31]$. Therefore, the residence time distribution in the grinding chamber is superposed by that in the storage tank and consequently the overall residence time distribution becomes wider. Especially at small comminution times, the circuit mode can lead to relatively wide particle size distributions with a tail of coarse particles. In contrast, the narrowest residence time distribution can be achieved by operat.

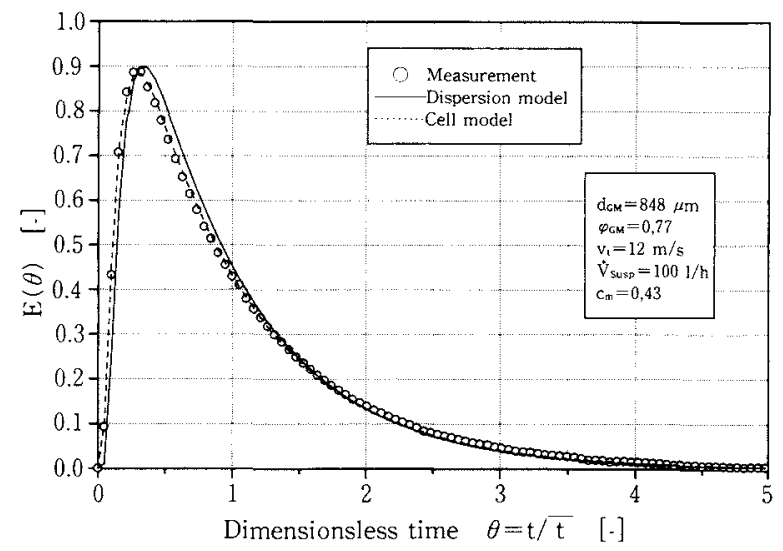

Fig. 11 Comparision of measured and calculated residence time distributions in a mill with disc stirrer 
bing w. N. more passes are carried out, the smaller the width of the particle size distribution. But because of high investment costs and a high expenditure for control technology, the multi-pass mode is not very common.

\section{Wear of grinding media}

The wear of grinding media was investigated extensively by Joost, Becker and Schwedes [25,27, 30], who made comminution tests with white fused alumina and other materials using varius grinding media materials. The wear of the grinding media was described by the ratio of the mass loss of the grinding media during the comminution process to the mass of the grinding media at the start of the comminution process, $\Delta \mathrm{m}_{\mathrm{GM}} / \mathrm{m}_{\mathrm{GM}}$. Figure 12 shows that the influence of the following operating param. eters on the wear of the grinding media can be described by the total energy input related to grinding chamber net volume, $\mathrm{E}_{\mathrm{V}, \mathrm{Gc}}$ : circumferential stirrer speed, $\mathrm{v}_{\mathrm{t}}$, mass flow rate, $\dot{\mathrm{m}}_{\text {susp }}$, and solids concentration by mass, $c_{m}$, of the product suspension, filling ratio, $\phi_{\mathrm{GM}}$, and size, $\mathrm{d}_{\mathrm{GM}}$, of the grinding media as well as grinding chamber geometry. Independent of the chosen operating parameters and independent of the grinding chamber geometry, a certain total energy input related to the grinding chamber net volume leads to the same media wear or to the same relative mass consumption of grinding media. Moreover, the media wear is affected by the properties of the media material and of the feed material, above all by the hardness of the two materials: The media wear decreases if harder grinding media or/and a softer feed material are employed.

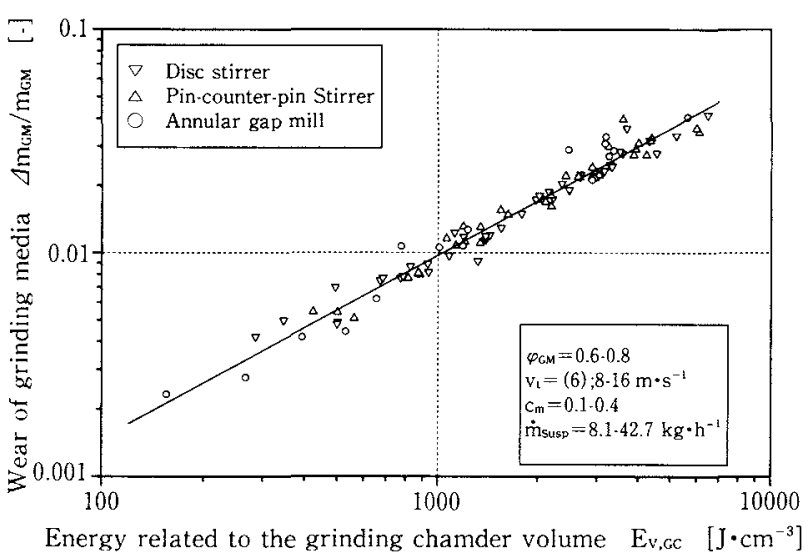

Fig. 12 Effect of different operating parameters on the media wear (comminution of white fused alumina) $[25,30]$

\section{Autogenous comminution}

By means of autogenous comminution, a product contamination caused by the breakage and abrasion of grinding beads can be avoided and grinding media costs can be largely reduced. Autogenous comminution in stirred media mills was scientifically investigated by The and Schubert [35] (silicon carbide), Kanda et al. [36] (limestone) and Kwade and Schwedes $[24,37,38]$ (limestone, white fused alumina). In Figure 13, the cumulative size distribution by mass, $Q_{3}$, is depicted for batch autogenous pebble comminution of limestone [24,37]. With the exception of the absence of fine feed (i.e. only coarse particles are in the mill), a fully autogenous comminution process is comparable.

Before starting the comminution process, the hold-up is composed of the grinding media (about 200 to $1600 \mu \mathrm{m}$ ) and the fine feed (about 20 to 100 $\mu \mathrm{m})$. After starting the comminution process, the feed particles are quickly reduced in size by the grinding media and a fine product with particle sizes smaller than $10 \mu \mathrm{m}$ results. Besides the feed particles, small grinding media which are stressed between large grinding media as well as grinding media with internal cracks are reduced in size by complete fracture. Moreover, chipping fracture (removal of asperities from irregular particles) occurs. After a few minutes, almost no particles can be found in the particle size range between the fine product and the grinding media or the pebbles, respectively, because pebbles are reduced in size mainly by the abrasion of micro grains and because small pebbles are broken by large pebbles before they become smaller than $100 \mu \mathrm{m}$. This particle size range without particles is very important for the separation of product and grinding media. Since the smallest size of the grinding media is larger than

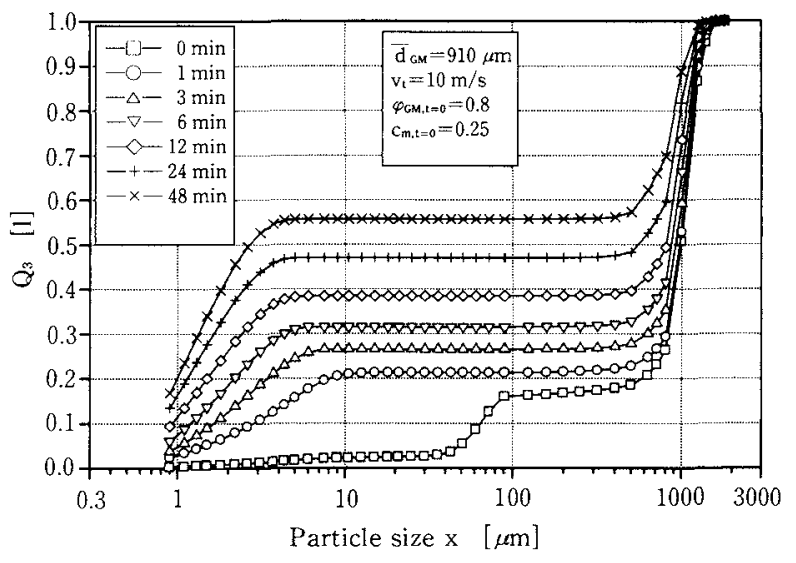

Fig. 13 Cumulative size distribution of the hold-up for batch autogenous pebble comminution of limestone 
$10 \mathrm{a}^{N} \mu \mathrm{m}$ and the product is finer than $10 \mu \mathrm{m}$, a product finer than $10 \mu \mathrm{m}$ can be achieved by sieving at a particle size of about $100 \mu \mathrm{m}$. Thus, a separation at a particle size of $10 \mu \mathrm{m}$ is not necessary to obtain a product finer than $10 \mu \mathrm{m}$. A comparison with the comminution of limestone using glass beads showed that the specific energy consumption of an autogenous comminution process is comparable to that using glass beads. Enderle et al. [2] give an example of an industrial use of autogenous comminution in stirred media mills. They report on the autogenous regrinding of zinc/lead ores in stirred media mills with disc stirrer and a grinding chamber volume of about 3000 litres and a drive with a power of $1.1 \mathrm{MW}$.

\section{Outlook}

The importance of stirred media mills for the production of very fine particles is likely to increase further in the next years. Because of rising product qualities, further developments of stirred media mills regarding the use of very fine grinding media, the production of narrow product particle size distributions and wear are expected. The research work should focus above all on the operation of stirred media mills, e.g. on the blocking of the grinding media, on the use of grinding aids and on the scale-up. Moreover, progress in the simulation of the comminution process should be made in a manner such that a prediction of the comminution result (product fineness, specific energy consumption) is possible for a wide range of operating parameters.

\section{References}

1) John, W. : Von der Trommelmühle zur Ringkammermü hle, Farbe und Lack, 79 (1973) 6, 537-542

2) Enderle, U., Woodall, P., Duffy, M. and Johnson, N.W.: Stirred Mill Technology for Regrinding McArthur River and Mount Isa Zinc/Lead Ores, XX International Mineral Processing Congress, 21.26. 9. 1997, Aachen, Germany

3) Stehr, N. : Recent Developments in Stirred Ball Milling, International Journal of Mineral Processing, 22 (1988) 431.444

4) Bosse, D.G.: Development and Use of the Sand Grinder, Official Digest, (1958) 3, 251-276

5) Engels, K. : Die Dispergierverfahren in der Lack- und Farbenindustrie unter besonderer Berücksichtigung der schnellaufenden Rührwerksmühlen, Farbe und Lack, 71 (1965) 5, 375-385
6) Hashi, Y., Senna, M.: Motion of Grinding Media in Axial Direction and its Effect on Comminution in an Agitation Bead Mill, KONA, 14 (1996) 176-181

7) Jenczewski, T.J.: The Grinding of Organic Dyestuffs, The Canadian Journal of Chemical Engineering, 50 (1972) 2, 59-65

8) Blecher, L., Kwade, A., Schwedes, J.: Motion and Stress Intensity of Grinding Beads in a Stirred Media Mill. Part 1: Energy density distribution and motion of single grinding beads, Powder Technology, 86 (1996), 59-68

9) Blecher, L.: Strömungsvorgänge in Rührwerkmühlen, Dissertation, TU Braunschweig, 1993

10) Stehr, N., Schwedes, J. : Technological Investigations on the Comminution at a Continuously Operated Ball Mill, Intern. Symp. on Recent Advances in Particulate Science and Technology, Madras, India, 1982, Part 1, Preprints, B103-B119

11) Stehr, N.: Zerkleinerung und Materialtransport in Rührwerkskugelmühlen, Dissertation, TU Braunschweig, 1982

12) Weit, H., Schwedes, J. : Scale-Up of Power Consumption in Agitated Ball Mills, Chem. Eng. Technol., 10 (1987) 6 , 398.404

13) Weit, H. : Betriebsverhalten und Maßstabsvergrößerung von Rührwerkskugelmühlen, Dissertation, TU Braunschweig, 1987

14) Weit, H., Schwedes, J. and Stehr, N. : Comminution and Transport Behaviour of Agitated Ball Mills, 1. World Congress Particle Technology, Nürnberg, 1987, Part II, Preprints, 709.724

15) Stehr, N., Weyand, C.: Control System for Agitated Media Mills, 7. European Symposium Zerkleinern, Ljubljana, 1990, 681.695

16) Stehr, N.: Naßfeinstmahlung mit Rührwerksmühlen in der Keramik-Grundlagen und technische Ausführungen, Keramische Zeitschrift 42 (1990) 3, 162/167

17) Mankosa, M.J., Adel, G.T., Yoon, R.H. : Effect of Media Size in Stirred Ball Milling Grinding of Coal, Powder Technology 49 (1986), 75-82

18) Stadler, N., Polke, R., Schwedes, J., Vock, F.: Naßmahlung in Rührwerksmühlen, Chem.-Ing.-Tech. 62 (1990) 11, 907-915

19) Bunge, F. : Mechanischer Zellaufschluß in Rührwerkskugelmühlen, Dissertation, TU Braunschweig, 1992

20) Bunge, F., Schwedes, J. : Mechanical Disintegration of Micro-Organisms, 7. Europ. Symposium Comminution, Ljubljana, June 1990, 55-77

21) Thiel, J.P.: Energiebedarf und Durchsatzverhalten der KohlenaBzerkleinerung in einer Rührwerkskugelmühle, Dissertation, TU Braunschweig, 1993

22) Thiel, J.P., Schwedes, J.: Comminution of Coal in an Agitated Ball Mill, Ljubljana, June 1990, 667-680

23) Kwade, A., Blecher, L., Schwedes, J. : Motion and Stress Intensity of Grinding Beads in a Stirred Media Mill. Part 2: Stress Intensity and its Effect on Comminution, Powder Technology, 86 (1996), 69-76

24) Kwade, A.: Autogenzerkleinerung von Kalkstein in Rührwerkmühlen, Dissertation, TU Braunschweig, 1996 
and Verlag Shaker, Aachen, 1997

25) Joost, B. : Zerkleinerung von Schmelzkorund und Mahlkörperverschleiß in Rührwerkskugelmühlen, Dissertation, TU Braunschweig, 1995

26) Reinsch, E., Bernhardt, C., Husemann, K. : Energy Consumption for Wet Grinding in Stirred Mills, Aufbereitungstechnik, 38 (1997) 3, 152-160

27) Becker, M., Schwedes, J. : Comminution of Ceramics in Stirred Media Mills and Wear of Grinding Beads, in Schwedes, J.: Feinste Feste Partikeln-Erzeugen, Klassieren, Abscheiden und Messen, Verlag Shaker, Aachen, 1997

28) Wang, Y., Forssberg, E. : Dispersants in Stirred Ball Mill Grinding, KONA 13 (1995), 67-77

29) Karbstein, H., Müller, F., Polke, R. : Scale-up for Grinding in Stirred Ball Mills, Aufbereitungstechnik, 37 (1996) 10, 469-479

30) Joost, B., Schwedes, J. : Comminution of White Fused Alumina and Wear of Grinding Beads in Stirred Media Mills, Ceramic Forum International, 73 (1996) 6 and 73 (1996) $7 / 8$

31) Karbstein, H., Müller, F., Polke, R. : Producing Suspensions with Steep Particle Size Distributions in Fines Ranges, Aufbereitungstechnik, 36 (1996) 10, 464.473

32) Stehr, N.: Residence Time Distributions in a Stirred
Media Mill and their Effect on Comminution, Chem. Eng. Process., 18 (1984), 73.83

33) Heitzmann, D.: Characterisation des Operations de Dispersion-Broyage, Dissertation, INPL Nancy, 1992

34) Berthiaux, H., Heitzmann, D., Dodds, J.A. : Validation of a model of a stirred bead mill by comparing results obtained in batch and continuous mode grinding, 8 . European Symposium on Comminution, Stockholm, 17. 19. 5. 1994, Preprints, Part II, 723-733

35) The, L.X., Schubert, H. : Autogene Mahlung von $\mathrm{SiC}$ in Rührwerksmühlen ohne und mit Mahlhilfsmitteln, Aufbereitungs-Technik 33 (1992) 10, 541-550 and 33 (1992) 12,661-664

36) Kanda, Y., Hasegawa, M., Hayashi, Y., Sano, S., Ishik awa, T., Nagaoka, H.: Production of Submicron Parti cles by Autogenous Grinding with a Stirred Mill, XVIII International Mineral Processing Congress, Sydney, 23. 28. 5. 1993, 245-249

37) Kwade, A., Schwedes, J.: Autogenous Comminution in Stirred Media Mills, 5th World Congress of Chemical Engineering, San Diego, 14.-18. 7. 1996, Preprints, 214-219

38) Joost, B., Kwade, A. : Feinstzerkleinerung in Rührwerk mühlen, in Reh, H. : Das Jahrbuch der Keramik, Bauver lag, Walluf, 1995, 23-38 


\section{Author's short biography}

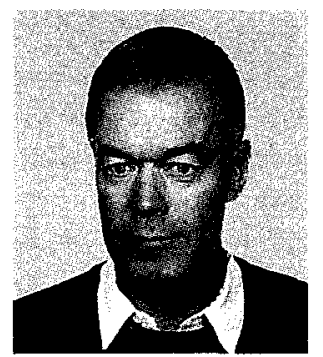

\section{Dr.-Ing. Jörg Schwedes}

Born 1938 in Berlin

Study of mechanical and chemical engineering at the Technical Unviersities of Karlsruhe and Munich. Dipl.-Ing. 1964 at Karlsruhe. Dr.-Ing. 1971 at Karlsruhe (Prof. Rumpf) with a thesis on the shear properties of slightly compressed cohesive granular materials.

1971-1976 with Bayer AG at Leverkusen as head of a research group working in the field of mechanical process engineering.

since 1976 Professor and Director of the Instiute of Mechanical Process Engineering, Technical University of Braunschweig.

main research activities:

- mechanics of bulk solids (measurement of flow properties, silo design, development and application of constitutive laws for bulk solids, instationary flow of gases in bulk solids, flow promoting devices, handing of contaminated soils)

- comminution (wet grinding in agitated ball mills, vibratory milling, grinding of micro-organisms, particle classification in the $\mu \mathrm{m}$-range)

about 130 publications

1982-1984 : Vicepresident of the Technical University of Braunschweig

1989-1991 : Dean of the Faculty of Mechnical Engineering

since 1991 : consultancy with Dr. Schulze on bulk solids technology

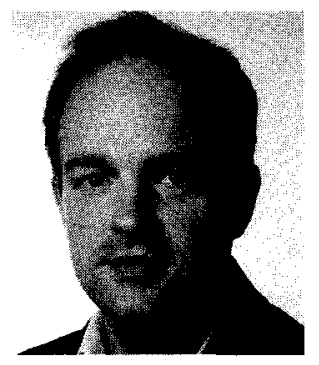

\section{Dr.-Ing. Arno Kwade}

Born 07. 01. 1965 in Nordhorn, Germany

1986-1992 : Study of Mechanical Engineering with consolidation in process and chemical engineering at the Technical University of Braunschweig, Germany, and the University of Waterloo, Canada (1989-1990)

1992-1996: Research assistant at the Institute of Mechanical Process Engineering of the Technical University of Braunschweig, Germany

1996: Dr.-Ing with a thesis on autogenous comminution of limestone in stirred media mills

1996: Foundation of the consultant and engineering company Kwade + Schwedes Zerkleinerungstechnik, Braunschweig, Germany

research activities : fine grinding, especially comminution in stirred media mills, and bulk solids handing 